\title{
A AVALIAÇÃO DE ESTUDANTES E PROFESSORES DE ADMINISTRAÇÃO SOBRE A EXPERIÊNCIA COM A APRENDIZAGEM BASEADA EM PROBLEMAS
}

\author{
EVALUATING MANAGEMENT STUDENTS AND PROFESSORS \\ REGARDING THEIR PROBLEM-BASED LEARNING EXPERIENCE
}

Recebido em: 16/07/2014 • Aprovado em: 30/o9/2014
Avaliado pelo sistema double blind review
Editora Científica: Manolita Correia Lima
DOI: $10.13058 /$ raep.2015.v16n1.201

\author{
KARINE DE LIMA GUEDES karinelguedes@yahoo.com.br \\ RUI OTAVIO BERNARDES DE ANDRADE \\ ALEXANDRE MENDES NICOLINI \\ UNIVERSIDADE DO GRANDE RIO
}

\section{RESUMO}

O objetivo do presente estudo foi verificar o impacto do uso da Aprendizagem Baseada em Problemas (ABP) na percepção dos estudantes e dos professores em uma instituição de ensino superior. A ABP é outra modalidade dentre as metodologias ativas e faz uso da resolução de problemas propostos para que o estudante analise e estude o conteúdo. Tal metodologia é formativa por estimular o estudante a ter uma postura ativa, por buscar o conhecimento. O estudo insere-se em uma abordagem qualitativa de pesquisa, pois buscou analisar uma proposta de ABP no ensino, tendo como universo de pesquisa professores e estudantes do curso presencial de graduação em Administração, de uma instituição privada. Os sujeitos analisados foram os estudantes matriculados no primeiro período do segundo semestre do ano de 2013 e os professores que lecionaram no segundo semestre do ano de 2013, as seguintes disciplinas no campus Lapa: Funções Executivas da Administração, Sociologia das Organizações, Evolução das Teorias da Administração, Desafios da Administração e Evolução das Teorias Econômicas. Para coleta de dados dos professores, empregou-se a técnica de entrevista semiestruturada e, para os estudantes, utilizou-se a técnica de Grupo Focal (GF). Com base na pesquisa realizada, observou-se que o método ABP, além de aproximar estudantes e professores para uma convivência mais proveitosa, possibilitou que os estudantes desenvolvessem um senso crítico e melhorou o quesito do trabalho em equipe, expandindo a visão sobre o problema, oportunizando uma pesquisa mais ampla, melhorando o raciocínio e a criatividade. Palavras-chave: Aprendizagem Baseada em Problemas (ABP); Ensino Superior; Administração.

\begin{abstract}
The aim of this study was to investigate the impact of Problem-Based Learning (PBL) from the points of view of students and teachers in a Higher Education Institute (HEI). PBL is one of the modalities within active methodologies and uses problem resolution for students to analyze and study content. This methodology educates through stimulating students to have a proactive attitude in seeking knowledge. The study utilizes a qualitative research approach and sought to analyze a PBL teaching proposal in with the sample groups coming from professors and students in an undergraduate Business Administration degree at a private institution. The subjects comprised students enrolled in the first period of the second half of 2013 and the professors lectured during that same period, for the following courses, at the Lapa campus: Executive Functions in Management, Sociology of Organizations, Management Theory Evolution, Management Challenges, and Economic Theory Evolution. Semi-structured interviews and Focus Groups (FG) were used to collect data from professors and students, respectively. The data showed the PBL method, in addition to bringing students and teachers together in more fruitful relationships, encouraged students to develop a critical sense and improved their teamwork skills, expanding their vision of the problem and thus providing opportunities for broader research and improving their reasoning and creativity. Keywords: Problem-Based Learning (PBL); Higher Education; Administration.
\end{abstract}




\section{INTRODUÇÃO}

$\mathrm{Na}$ era da internet, os estudantes se beneficiam com a velocidade com que as informações chegam, criando, nesses jovens, características diferentes dos jovens de épocas anteriores; assim, uma nova forma de aprender é exigida, voltada principalmente para a prática do dia a dia. É preciso promover, nos estudantes, a autonomia, para que possam buscar novos conhecimentos ao longo de sua vida profissional.

As metodologias ativas fundamentam-se no princípio da autonomia. $\mathrm{Na}$ educação moderna, o discente precisa desenvolver capacidade de gerenciamento e administração do seu processo de formação (FREIRE, 2006). O ensinar, nesta abordagem progressista que considera o indivíduo como construtor da sua própria história, exige do professor respeito à autonomia de cada estudante (COSTA; SIQUEIRA-BATISTA, 2004).

$\mathrm{Na}$ metodologia tradicional, o ensino se preocupa mais com a variedade e quantidade de noções, conceitos e informações, do que com a formação do pensamento reflexivo do estudante. Aqui, o professor não é o mediador; é aquele que detém o poder dentro da sala de aula. O professor detém os meios coletivos de expressão. A maior parte dos exercícios de controle e de exames se orientam para a reiteração dos dados e informações anteriormente fornecidas pelos manuais (MIZUKAMI, 1986).

Hoje, o mercado de trabalho exige profissionais com capacidade de resolução de problemas, habilidade para trabalhar em equipe, ética profissional e cidadania. Para que esses estudantes adquiram esses atributos, as instituições de ensino precisam experimentar alternativas, com o objetivo de melhorar o processo de ensino-aprendizagem; buscando novas metodologias, saindo da abordagem em que o professor tem um papel ativo e o estudante um papel passivo. Dessa forma, procura-se uma metodologia que esteja centrada no estudante, na qual o mesmo é o principal responsável pelo seu desenvolvimento.

Frente a essas necessidades, as universidades têm utilizado como estratégia de ensino as metodologias construtivistas, como a Aprendizagem Baseada em Problemas (ABP), que apresenta uma potencialidade para 
A APRENDIZAGEM BASEADA EM PROBLEMAS

desenvolver habilidades e atitudes de forma integrada e, assim, melhora o processo de ensino-aprendizagem.

O presente trabalho pretende aplicar metodologias ativas de aprendizagem, em especial, Aprendizagem Baseada em Problemas (ABP), aos cursos de Administração, sob a perspectiva dos estudantes e dos professores. Portanto, o problema de pesquisa foi definido: Como a Aprendizagem Baseada em Problemas é percebida por estudantes e professores de graduação em Administração? 


\section{REFERENCIAL TEÓRICO}

Ensinam Cabral e Teodosio (2010) que, a palavra pedagogia se originou na Grécia antiga, paidós (criança) e agogé (condução), configurando-se, etimologicamente, como a condução da criança ao saber. A palavra grega paidagogos é formada pela palavra paidós (criança) e agogos (condutor). Pedagogo, portanto, significa condutor de crianças ao saber. Dessa forma, a pedagogia está vinculada à ação de condução do saber e, até hoje, a preocupação da pedagogia é encontrar formas de levar o indivíduo ao conhecimento. Pode-se considerar a Grécia clássica como o berço da pedagogia, pois foi exatamente lá que surgiram as primeiras ideias e ponderações quanto à atuação pedagógica que continuarão influenciando a educação e a cultura ocidental.

Os educadores de adultos devem se esforçar para não serem vistos apenas como o professor, mas como um facilitador. Assim, os professores são solucionadores de problemas, sendo questionados e desafiados, adaptandose ativamente para atender às necessidades dos estudantes e desenvolvem uma consciência mais ampla de oportunidades de ensino fora da sala de aula, ao considerar a comunidade educacional como um todo (BEAVERS, 2009).

\section{METODOLOGIA DE ENSINO-APRENDIZAGEM TRADICIONAL}

De acordo com Abreu e Masetto (1985), a metodologia tradicional é aquela na qual primeiro o professor apresenta a teoria, para depois realizar a prática. Para Mizukami (1986), a ênfase é dada às situações de sala de aula, onde os estudantes são "instruídos" e "ensinados" pelo professor. Os conteúdos e as informações têm de ser adquiridos, os modelos imitados. Seus elementos fundamentais são imagens estáticas, que progressivamente serão "impressas" nos estudantes, cópias de modelos do exterior que serão gravadas nas mentes individuais.

A aula é expositiva, o conteúdo é pré-elaborado, geralmente ensinado por meio de livros, e o estudante se limita exclusivamente a escutá-lo. No método expositivo, o professor é o agente e o estudante é o ouvinte. Mesmo que ele não compreenda o conteúdo, a aula continua e esse nível de compreensão só será visto após as provas. 


\section{METODOLOGIA ATIVA DE APRENDIZAGEM}

A implantação de metodologias ativas no processo de ensino-aprendizagem consiste em enfrentar muitos desafios, pois o estudante passa a ser o protagonista desse processo e os professores assumem o papel de mediadores. As metodologias ativas fundamentam-se em estratégias de ensino baseadas nas concepções pedagógicas reflexivas e críticas, onde se pode interpretar e intervir sobre a realidade, promover a interação entre as pessoas e valorizar a construção do conhecimento, os saberes e situações de aprendizagem (FEUERWERKER; SENA, 2002).

As metodologias ativas fundamentam-se no princípio da autonomia. $\mathrm{Na}$ educação moderna, o discente precisa desenvolver capacidade de gerenciamento e administração do seu processo de formação (FREIRE, 2006). O ensinar, nesta abordagem progressista, que considera o indivíduo como construtor da sua própria história, exige do professor respeito à autonomia de cada estudante (COSTA; SIQUEIRA-BATISTA, 2004).

$\mathrm{Na}$ metodologia ativa busca-se promover processos de ensinoaprendizagem crítico-reflexivos, onde o estudante se torna mais participativo e comprometido com seu aprendizado. Em sua proposta, procura apresentar situações de ensino que despertem maior senso crítico do estudante com a realidade, que o faça refletir sobre problemas desafiadores, a identificar e organizar determinadas hipóteses de soluções que mais se enquadrem à situação; e a aplicação destas (LUCKESI, I99I; DIAZ-BORDENAVE; PEREIRA, 2007).

O estudante passa a assumir um papel mais ativo, rompendo com o estigma de simples receptor de conteúdo, e a buscar conhecimentos voltados especificamente aos problemas e objetivos da aprendizagem. Em decorrência dessa nova postura, o estudante passa a desenvolver em seu perfil, características como responsabilidade, autoavaliação, ética, trabalho em equipe, ser mais crítico-reflexivo, criatividade e curiosidade científica (MITRE et al., 2008). Segundo essa autora, as metodologias ativas empregam a problematização como estratégia de ensino/aprendizagem, buscando alcançar e motivar o estudante que, diante do problema, apreende, analisa, reflete, busca relacioná-lo com sua história e desenvolve um novo significado 
às suas descobertas. Aprender por intermédio da problematização, da resolução de problemas específicos de suaárea, promove o comprometimento ativo dos estudantes em seu processo de formação.

São exemplos de metodologias ativas: a aprendizagem baseada na reflexão sobre a experiência (KOLB, 1984), Aprendizagem Baseada em Problemas (ABP) ou Problem-Based Learning (PBL), Estudo de Caso, Ciclos de Aperfeiçoamento da Prática Profissional (CAPP) (Peer Review) e Intervenções multifacetadas.

A Aprendizagem Baseada em Problemas (ABP) foi introduzida no Brasil, primeiramente, no curso de Medicina. A ABP faz uso da resolução de problemas propostos para que o estudante analise e estude o conteúdo. Tal metodologia é formativa, por estimular o estudante a ter uma postura ativa, por buscar o conhecimento (SAKAI; LIMA, 1996).

$\mathrm{Na}$ metodologia ativa, o estudante se coloca ao lado do professor, que atua como orientador das atividades educativas, como um participante que também busca o conhecimento. A ação de dialogar com esses estudantes não significa, simplesmente, delegar toda a elaboração do problema a eles, mas levá-los a analisar, de maneira profunda, a problemática, com o objetivo de que eles possam descobrir a totalidade e predispor-se a desnudá-la para responder às questões propostas (MOREIRA; FONTENELE, 20II).

\section{DEFINIÇÃO E CARACTERIZAÇÃO DA APRENDIZAGEM BASEADA EM PROBLEMAS}

A Aprendizagem Baseada em Problemas (ABP) ou Problem-Based Learning (PBL) originou-se na Escola de Medicina da Universidade McMaster, no Canadá, ao final dos anos 60. É uma metodologia de ensino e aprendizagem muito utilizada no ensino superior, que emprega problemas da vida real (reais ou simulados), para que o estudante possa aprender por meio da dúvida, deixando de lado o papel de receptor e tornando-se construtor do próprio conhecimento. A ABP pode ser considerada uma metodologia, que utiliza situações complexas, para instigar os estudantes a pesquisarem soluções para problemas. Ela baseia-se no princípio do uso de problemas, como ponto inicial para aquisição do conhecimento, situando a aprendizagem em problemas cotidianos, reforçando o aprendizado já existente. 
A ABP tem sido utilizada em vários níveis educacionais e no ensino superior, especialmente nos cursos de Medicina, Enfermagem, Pedagogia, Administração e Engenharia. Os princípios da aprendizagem que formam a base da ABP parecem derivar das teorias de Ausubel, Bruner, Dewey, Piaget e Rogers (RIBEIRO, 2005).

A ABP é considerada uma proposta didática com a finalidade de obter conhecimentos por meio da resolução de problemas. Barrows (I996 apud HMELO-SILVER, 2004), afirma que, como proposta didática, a ABP possui características como: Aprendizagem centrada no estudante; aprendizagem ocorre em grupos pequenos de estudantes; professores atuam como facilitadores ou guias; os problemas funcionam como objetivo da organização e estímulo para a aprendizagem; os problemas conduzem para o desenvolvimento de capacidades de resolução de problemas e; novo conhecimento se origina em decorrência da aprendizagem autodiretiva.

Segundo Schmidt (I993), são componentes necessários para o desenvolvimento da ABP: o problema, os grupos tutoriais, o facilitador, o currículo e o estudo individual.

O elemento central da metodologia ABP é o problema, por haver o confronto com ele já no começo da aprendizagem. Wilkerson e Feletti (1989) ressaltam a importância de o problema abordar assuntos importantes para a aprendizagem do estudante, envolvendo-o na discussão, de modo a haver troca de experiências entre os membros.

O grupo tutorial é formado pelos estudantes e pelo facilitador/tutor. Entre os estudantes, delega-se a um deles a função de coordenador e outro a outro a de redator da sessão tutorial. Mamede et al. (200I) consideram que, no grupo tutorial, o problema aplicado é analisado e os objetivos de aprendizagem são estabelecidos. No grupo tutorial acontece a aprendizagem no contexto vivencial do cotidiano e a motivação individual. Dessa forma, o facilitador/tutor deve observar a presença desses fatores e se eles estão sendo desenvolvidos na execução da atividade aplicada no grupo.

Quanto ao facilitador, Frost (1996) ensina que, sua função principal no grupo éinstigar os estudantes a pesquisar e refletir a respeito do conhecimento que já possuem sobre o tema aplicado e a buscar novos objetivos nesta 
aprendizagem. Segundo Schmidt (1993), a missão do facilitador é utilizar os meios de pesquisa à disposição, interferir apresentando pontos relacionados, recomendar ações e diretrizes e repassar aos grupos como está o andamento do trabalho.

Mamede et al. (2000) consideram que os currículos que usam a metodologia ativa ABP precisam estruturar-se diferentemente dos currículos tradicionais, que são em disciplinas. Sua estruturação deve ser em unidades ou blocos temáticos, onde os problemas apresentados e estudados se interrelacionam, orientando o aprendizado por diferentes aspectos relacionados ao tema principal.

Ensinam Cyrino e Pereira (2004) que, a ABP trabalha intencionalmente com problemas, para o desenvolvimento dos processos de ensinar e aprender, apoiada na aprendizagem por descoberta e significativa, valorizando o aprender a aprender, trabalhando a construção de conhecimentos com base na vivência de experiências significativas. Apoiada nos processos de aprendizagem por descoberta, em oposição aos de recepção (em que os conteúdos são oferecidos ao estudante em sua forma final), os conteúdos de ensino não são oferecidos aos estudantes em sua forma acabada, mas na forma de problemas, cujas relações devem ser descobertas e construídas pelo estudante, que precisa reorganizar o material, adaptando-o à sua estrutura cognitiva prévia, para descobrir relações, leis ou conceitos que precisará assimilar.

A metodologia ora comentada objetiva a interdisciplinaridade e a prática. Para isso, organiza-se um elenco de situações que o estudante deverá saber/ dominar, considerando o tipo de organização curricular, apresentando ao estudante ou grupo de estudantes, um determinado problema por um professor, devendo ser discutido em grupo, incentivando-se o levantamento de hipóteses para explicá-lo. Os problemas são formulados e selecionados para serem apresentados a cada período do curso, no qual se espera que os estudantes consigam produzir alguma teoria, mas sempre com a proposta de que uma teoria mais completa seja buscada.

Nii e Chin (1996) afirmam que este método proporciona conhecimento aos estudantes por meio de um processo de aprendizagem ativo, pois se 
acredita ser melhor do que aprendido por meio de métodos convencionais passivos. A justificativa para a Aprendizagem Baseada em Problemas centrase na ideia de que ela melhora as estratégias de raciocínio indutivo que podem ser mais eficazes para a aprendizagem. O sucesso dessa estratégia de ensino oferece flexibilidade educacional, pois os estudantes e professores se envolvem em um processo de descoberta em conjunto, na qual o professor estimula os estudantes ao diálogo, à reflexão, à autonomia e ao aproveitamento das oportunidades de aprendizagem.

\section{LIMITES DA APRENDIZAGEM BASEADA EM PROBLEMAS}

Uma questão polêmica na metodologia ABP é quando há mudança no currículo. Na ABP é necessária a construção de um currículo baseado em problemas. A abordagem formativa centrada na resolução de problemas seria a diretriz norteadora em todo processo educativo. Essa abordagem curricular busca confrontar os estudantes, por exemplo, com situações vivenciadas profissionalmente e no dia a dia.

$\mathrm{Na}$ visão dos professores, utilizar novas abordagens pedagógicas pode acarretar dúvidas e com certeza eles irão se deparar com situações imprevistas e de risco. Caso os estudantes não sejam habituados a essa nova abordagem pedagógica certamente aprenderão menos no início.

Ribeiro (2008) ressalta que, a ABP não é uma metodologia que venha resolver os problemas na educação, assim como, também, não abarca todos os estilos de aprendizagem. Existem os estudantes que lidam bem com o trabalho em grupo, desenvolvimento em equipe, mas, por outro lado, há também estudantes competitivos, individualistas e introvertidos que podem não se adaptar à nova dinâmica ativa, de participação e colaboração da aprendizagem inserida na ABP. 


\section{METODOLOGIA}

O presente trabalho utilizou como metodologia a pesquisa bibliográfica em livros, artigos, revistas científicas, dissertações e teses disponíveis nas principais bibliotecas virtuais sobre a Aprendizagem Baseada em Problemas. Insere-se em uma abordagem qualitativa de pesquisa, pois buscou analisar a aplicação da Aprendizagem Baseada em Problemas no ensino do curso de Administração.

Estabeleceu-se como unidade de observação, professores e estudantes do curso de graduação em Administração, modalidade presencial, de uma instituição privada de ensino superior no campus Lapa, na cidade do Rio de Janeiro - RJ.

A unidade de análise de professores foi formada por aqueles que lecionaram no segundo semestre do ano de 2013, as seguintes disciplinas: Funções Executivas da Administração, Sociologia das Organizações, Evolução das Teorias da Administração, Desafios da Administração e Evolução das Teorias Econômicas. A amostra de estudantes analisada foi formada por aqueles que se matricularam no primeiro período do segundo semestre do ano de 2013.

\section{INSTRUMENTO DE PESQUISA}

Na coleta de dados utilizou-se a técnica de Grupo Focal (GF) com três estudantes, que é uma técnica qualitativa realizada por meio de entrevistas grupais.

Para a coleta de dados com os cinco professores empregou-se a técnica de entrevista semiestruturada.

Para interagir com os estudantes e professores e verificar a percepção deles quanto ao método utilizado, optou-se pela técnica de grupo focal e de entrevistas semiestruturadas que auxiliou a pesquisadora na busca por informações, tomando por regra a fala dos atores sociais.

\section{PROTOCOLO DA APRENDIZAGEM BASEADA EM PROBLEMAS}

Os grupos escolhidos por solucionar o problema são chamados de Grupos Tutoriais (GT) e compostos por, no máximo, ro estudantes, sendo cada grupo 
A AVALIAÇÃO DE ESTUDANTES E PROFESSORES DE ADMINISTRAÇÃO SOBRE A EXPERIÊNCIA COM

A APRENDIZAGEM BASEADA EM PROBLEMAS

orientado por um único professor. No GT, o professor atua como facilitador/ tutor, não dando respostas prontas, apenas mediando os estudantes na busca de soluções. A dinâmica do GT obedece a uma técnica própria. 


\section{O PROCESSO DE APRENDIZAGEM BASEADA EM PROBLEMAS NA} SALA DE AULA

1. Primeiro dia: Passo r: A pesquisadora, junto com o professor, separou os estudantes em grupos de no máximo io pessoas, explicou a metodologia e entregou o material contendo a situação-problema, um guia de instruções, o relatório parcial e o final. Passo 2: Os estudantes fizeram a leitura do problema (análise do cenário) e depois o professor conduziu a discussão para saber como cada grupo entendeu o problema, pontuando cada tópico para que todos tivessem o mesmo entendimento. O objetivo desse passo foi fazer com que o estudante verificasse a compreensão do cenário mediante a discussão do mesmo dentro de seu grupo de trabalho.

2. Segundo dia: Passo 3: Foi realizada um brainstorming pelos estudantes. As ideias do grupo foram registradas no relatório parcial para serem aceitas ou descartadas conforme o avanço na investigação. $O$ objetivo foi registrar o máximo de ideias possíveis. Passo 4: Após o brainstorming, foi feita uma revisão de tudo aquilo que o grupo conhece sobre o problema ou a situação apresentada.

3. Terceiro dia: Passo 5: Foi feita uma lista com aquilo que o grupo achava que devia saber para resolver o problema, elaborando a lista daquilo que se desconhecia. Passo 6: Os estudantes planejaram as estratégias de investigação e elaboraram uma lista das ações que deviam ser realizadas. O professor pediu aos estudantes que fizessem uma pesquisa individual em casa que seria compartilhada com o grupo na aula seguinte. Essa é a fase de estudo individual, na qual cada integrante do grupo, seguindo o plano de ação definido pelo grupo, deveria localizar, registrar, organizar, analisar e interpretar as informações de diversas fontes.

4. Quarto dia: Passo 7: Os grupos definiram o problema e elaboraram declarações que explicassem claramente o que o grupo deveria resolver, produzir ou responder. Passo 8: O grupo apresentou o que aprendeu durante a fase de estudo individual, reavaliaram o problema à luz dos 
novos conhecimentos adquiridos e confeccionaram o relatório final.

5. Quinto dia: Passo 9: Os estudantes apresentaram as recomendações, previsões e deduções em relação à resolução do problema. No fim das apresentações o professor destacou para os estudantes os principais acertos e dificuldades, visando ao aprimoramento do desenvolvimento conceitual. Passo ıo: Os estudantes fizeram a avaliação dos pares e a autoavaliação. Ao término de todo o processo, a pesquisadora recolheu todo material desenvolvido: relatório parcial, relatório final, avaliação. Todos os materiais entregues foram objetos de investigação na pesquisa.

\section{ANÁLISE E INTERPRETAÇÃO DOS DADOS COLETADOS}

Finalizada a coleta de dados, as entrevistas foram organizadas permitindo a reprodução das falas dos sujeitos. Quanto à análise de interpretação, essa foi realizada tendo como base o discurso dos professores e estudantes do curso de Administração. Nesse contexto, estabeleceu-se o método de análise de conteúdo com técnica qualitativa, para o tratamento dos dados coletados. 


\section{ANÁLISE DOS RESULTADOS}

\section{PROFESSORES}

A maioria dos professores não teve grandes dificuldades com a utilização do método, pois já praticava ou conhecia as metodologias ativas, mas segundo o entrevistado PI, agora o método está mais estruturado. Ele percebeu que, com a utilização das metodologias ativas, há uma integração de todo o conhecimento entre as disciplinas e disse ainda que foi uma experiência positiva, mas que o processo ainda precisa de ajustes, mas tem tudo para melhorar.

$\mathrm{O}$ entrevistado $\mathrm{P}_{3}$ gostou da maneira sistemática como foi conduzida e achou que foi bem proveitoso. $\mathrm{O}$ entrevistado $\mathrm{P}_{5}$ ficou surpreso com o desempenho dos estudantes e achou bastante válida a utilização do método.

Os entrevistados Pı e $\mathrm{P}_{5}$ consideraram a experiência interessante, apesar do entrevistado P2 dizer que teve certa dificuldade no início para interagir com essa nova metodologia, pois estava habituado com a metodologia tradicional que era a exigida pela instituição.

De acordo com Feuerwerker e Sena (2002), a implantação de metodologias ativas no processo de ensino aprendizagem consiste em enfrentar muitos desafios, pois o estudante passa a ser o protagonista desse processo e os professores assumem o papel de mediadores.

Esses resultados vão ao encontro dos estudos de Abreu (2009), para quem a metodologia tradicional é aquela na qual primeiro o professor apresenta a teoria, para depois realizar a prática. Para Mizukami (1986), a ênfase é dada às situações de sala de aula, onde os estudantes são "instruídos" e "ensinados" pelo professor. Os conteúdos e as informações têm de ser adquiridos, os modelos imitados. Seus elementos fundamentais são imagens estáticas, que progressivamente serão "impressas" nos estudantes, cópias de modelos do exterior que serão gravadas nas mentes individuais.

$\mathrm{O}$ entrevistado $\mathrm{P} 2$ disse que, ao longo das aulas, os estudantes falavam que já haviam escutado sobre aquele assunto, assim, ele percebeu que estava alcançando pelo menos uma parte da proposta. 
Nesse sentido, Luckesi (199I), Diaz-Bordenave e Pereira (2007) afirmam que, com a metodologia ativa, o estudante torna-se mais participativo e comprometido com seu aprendizado.

$\mathrm{O}$ entrevistado $\mathrm{P}_{3}$ leu o material que foi disponibilizado com o planejamento de cada dia para se envolver com a etapa que a turma se encontrava. $\mathrm{O}$ entrevistado $\mathrm{P}_{5}$ questionou o uso da problematização semanalmente, mas sugeriu sua utilização periodicamente dentro de um semestre para todas as disciplinas.

Luckesi (I99I), Diaz-Bordenave e Pereira (2007) destacam que a metodologia ativa procura apresentar situações de ensino que despertem maior senso crítico do estudante com a realidade, que o faça refletir sobre problemas desafiadores, a identificar e organizar determinadas hipóteses de soluções que mais se enquadrem à situação e a aplicação de tais soluções.

$\mathrm{O}$ entrevistado $\mathrm{P}_{4}$ afirmou que os estudantes têm dificuldade de correlacionar o conteúdo que eles aprendem, com aquilo que é instrumento para resolver um problema e, mais dificuldade ainda, em identificar o problema e separar o que é problema e o que é solução. Esse mesmo entrevistado afirmou que, os estudantes não sabem dividir tarefas e nem trabalhar em grupo e sempre existem alguns que se engajam mais e outros menos, e que nessa experiência houve casos de estudantes que não participaram nada ou pouco.

Essas dificuldades podem ser explicadas por Abreu (2009), pois os estudantes estão acostumados com a metodologia tradicional, onde a aula é expositiva, o conteúdo é pré-elaborado, geralmente ensinado por meio de livros, e o estudante se limita exclusivamente a escutá-lo. No método expositivo, o professor é o agente e o estudante é o ouvinte. Mesmo que ele não compreenda o conteúdo a aula continua e esse nível de compreensão só será visto após as provas.

$\mathrm{O}$ entrevistado $\mathrm{P}_{4}$ falou ainda que o problema não foi da aplicação do método. Ele considera como um problema estrutural que envolve desde a formação escolar, a falta de cobrança e que o estudante fica perdido na sala de aula. Então, envolve uma série de questões que acabaram sendo reproduzidas nessa atividade. 
Esses resultados vão ao encontro das afirmações de Abreu (2009), pois na metodologia tradicional, utilizada durante anos, os estudantes com melhor poder aquisitivo têm aulas particulares ou de reforço, para conseguir compreender a matéria e isso fez com que os estudantes ficassem engessados, sem criatividade e sem desenvolver senso crítico.

Para os entrevistados $\mathrm{P}_{1}, \mathrm{P}_{2}, \mathrm{P}_{3}, \mathrm{P}_{4}$ e $\mathrm{P}_{5}$, o protocolo é válido. Para os entrevistados $\mathrm{P}_{1}, \mathrm{P}_{2}$ e P3 , a utilização do protocolo para aplicação do método, sem dúvida nenhuma, contribuiu, tendo sido um dos fatores decisivos para a promoção do processo de ensino e aprendizagem.

$\mathrm{O}$ entrevistado $\mathrm{P} 2$ também afirma que o uso do protocolo contribuiu e que o aproveitamento da turma do projeto foi superior, no sentido da aprendizagem em relação às outras turmas que usam o método tradicional; para esse entrevistado, os resultados positivos puderam ser observados na primeira avaliação.

$\mathrm{O}$ entrevistado $\mathrm{P}_{5}$ viu apenas o resultado, não tendo acompanhado a aplicação do protocolo, mas por causa dos bons resultados, entende ser válida sua utilização.

$\mathrm{O}$ entrevistado $\mathrm{P}_{3}$ entende que a aplicação por etapas auxilia no aprendizado, mas que os professores precisam de maturidade, de maior conhecimento sobre o assunto, ou seja, precisam se preparar melhor, estudar mais, porque o professor precisa realizar todo um trabalho de preparação até o estudante se acostumar, visto que estão acomodados com o método tradicional, que traz tudo pronto.

Esses resultados lembram a afirmação de Freire (2006), para quem as metodologias ativas fundamentam-se no princípio da autonomia. $\mathrm{Na}$ educação moderna, o discente precisa desenvolver capacidade de gerenciamento e administração do seu processo de formação. O ensinar nesta abordagem progressista, que considera o indivíduo como construtor da sua própria história, exige do professor respeito à autonomia de cada estudante (COSTA; SIQUEIRA-BATISTA, 2004).

$\mathrm{O}$ entrevistado $\mathrm{P}_{4}$ acha que o protocolo é válido, mas que precisa ser mais bem detalhado, porque, segundo ele, os estudantes não estão preparados, não sabem o que significam questão de pesquisa e nem problema. Entende 
que, antes de aplicar o protocolo, é interessante ter leitura prévia do conteúdo. Para esse entrevistado, as questões de metodologia científica precisam ser mais bem explicadas ao estudante.

Para os entrevistados $\mathrm{P}_{\mathrm{i}}$ e $\mathrm{P}_{3}$, a dificuldade estava relacionada ao estudante e à sua falta de comprometimento. O entrevistado $\mathrm{P}_{2}$ afirmou que as dificuldades foram mais sentidas no primeiro bimestre, relativas ao tempo de aula e ao tempo completo de aplicação do método. Não mencionou as dificuldades dos estudantes, apenas suas próprias dificuldades em aplicar o método no tempo de quatro aulas, afirmando que seria necessário um tempo maior.

Para PI, a dificuldade maior é a falta de preparo dos estudantes, aliada à falta de interesse e comprometimento. Afirma que, os estudantes escolhem o curso de Administração, por entenderem ser o mais fácil e ao se depararem com as exigências de leitura e compreensão de textos, desanimam. Muitos não possuem boa formação no nível de ensino fundamental e médio e isso dificulta.

$\mathrm{P}_{2}$ afirmou que as dificuldades foram mais sentidas no primeiro bimestre, por estar se adequando ao método e, no segundo, por fatores externos que causaram a ausência dos estudantes, como por exemplo, as chuvas.

Para $\mathrm{P}_{3}$, as dificuldades dos estudantes já eram esperadas, pois alguns trabalham, os estudantes estavam em semana de provas, acumulada com a necessidade de elaboração de trabalhos e a falta de conhecimento do método também ajudou. $\mathrm{P}_{4}$ afirma que é preciso ter mecanismos que façam que todos trabalhem.

Para Moreira e Fontenele (20II), na metodologia ativa o estudante se coloca ao lado do professor, que atua como orientador das atividades educativas, como um participante que também busca o conhecimento. A ação de dialogar com esses estudantes não significa, simplesmente, delegar toda a elaboração do problema a eles, mas levá-los a analisar, de maneira profunda, a problemática, com o objetivo de que eles possam descobrir a totalidade e predispor-se a desnudá-la para responder às questões propostas, o que pode se tornar bem difícil para quem não está acostumado.

Os entrevistados $\mathrm{P}_{1}, \mathrm{P}_{2}, \mathrm{P}_{3}$ e $\mathrm{P}_{5}$ entendem que houve grande interesse por 
parte dos estudantes. $\mathrm{O}$ entrevistado $\mathrm{P}_{4}$ não pode opinar porque, como já mencionado, só esteve presente no último dia e não acompanhou a turma.

O entrevistado Pi ressalta que os estudantes gostaram e acharam interessante; a receptividade dos estudantes ao método foi maior que a do método tradicional, ressaltando que um dos estudantes que costumava ser mais resistente elogiou o método.

$\mathrm{O}$ entrevistado $\mathrm{P}_{2}$ considera que os estudantes receberam bem o novo método. $\mathrm{O}$ entrevistado $\mathrm{P}_{3}$ também afirmou que os estudantes ficaram mais entusiasmados com o método e que houve maior envolvimento nas atividades.

$\mathrm{O}$ entrevistado $\mathrm{P}_{5}$ também considerou que os estudantes ficaram entusiasmados e que tiveram participação ativa nas aulas. O entrevistado ressaltou que a turma foi mais participativa, respondendo melhor ao método. A nova metodologia estimulou até mesmo aos menos empolgados, que tinham menos experiência prática.

Para Westberg e Jason (1993), trabalhar com pequenos grupos contribui para que haja condições propícias para o processo de aprendizagem, pois promove a cooperação e a aprendizagem entre os integrantes e a construção de conhecimentos.

$\mathrm{O}$ entrevistado $\mathrm{P}_{4}$ considerou que a falta de engajamento de alguns estudantes ocorreu devido à formação de grupo com mais de três pessoas, pois nesse caso, sempre tem um estudante cuja participação não é cobrada devidamente.

O entrevistado $\mathrm{P}_{5}$ considerou que nem todos os estudantes participaram ativamente, especialmente aqueles que trabalharam em grupo, onde tem sempre um estudante que não participa.

Os entrevistados $\mathrm{P}_{1}, \mathrm{P}_{3}$ e $\mathrm{P}_{5}$ entendem que o impacto foi positivo. $\mathrm{O}$ entrevistado $\mathrm{P}_{2}$ percebeu que surgiram aspectos de lideranças nos grupos, que não tinha sido percebido antes. $\mathrm{O}$ entrevistado Pi disse que não tinha meios de avaliar o impacto da aprendizagem, mas percebeu reações positivas ao método.

$\mathrm{O}$ entrevistado $\mathrm{P}_{2}$ afirmou que, apesar dos estudantes se perderem no conteúdo, ou seja, não saberem de quem era tal conteúdo ou teoria, 
conseguiam aplicá-lo ao problema.

$\mathrm{O}$ entrevistado $\mathrm{P}_{3}$ não viu o resultado final, mas afirmou que todos buscaram fazer link, não necessariamente com sua disciplina, mas sim com o curso, pois a preocupação era com o modelo que é mais interdisciplinar, relacionando sua disciplina com a de outros professores e do curso em geral.

$\mathrm{O}$ entrevistado $\mathrm{P}_{4}$ diz não poder avaliar se houve ou não impacto na aprendizagem porque o tempo de aplicação do método foi apenas de uma semana, mas que serviu para mostrar aos estudantes que eles são ignorantes. Considerou que, se estudantes que estão terminando a graduação têm dificuldades, o que não falar de quem está apenas começando. Também afirmou que não houve discrepância, ou seja, se for comparado o antes e o depois, não houve nenhuma mudança de comportamento por parte dos estudantes após as atividades.

$\mathrm{O}$ entrevistado $\mathrm{P}_{5}$ afirmou que a turma, além de apresentar os problemas, apontava soluções. Os estudantes associaram as teorias econômicas a como ganhar dinheiro com essas soluções apresentadas. Faltou a associação da disciplina, do pensamento econômico, o capitalista principalmente, para pensar em como ganhar dinheiro com essa situação.

\section{ESTUDANTES}

Para os três estudantes que participaram do grupo focal, existem claramente diferenças entre um método e outro. Com o método ativo, segundo eles, ficou mais fácil vivenciar as situações dentro de uma empresa, deu uma visão diferente, pois na teoria há apenas suposições e na aplicação prática os estudantes puderam testar o que realmente aprenderam e aplicar naquele tipo de situação.

Os três estudantes entrevistados tiveram a mesma opinião. Sentiram muitas dificuldades no início das atividades, porque não sabiam como começar e alguns dos professores não interferiram, deixando-os à vontade. Nos últimos dias das atividades, os professores procuraram questioná-los, procuraram ajudar, instigando-lhes a memória sobre o que já haviam aprendido em sala de aula e levantando o debate sobre o assunto em pauta e isso ajudou muito, mesmo que não dessem respostas aos problemas, 
procurando fazer com que os estudantes pensassem e desenvolvessem seu próprio raciocínio.

De acordo com Mitre et al. (2008), o estudante passa a assumir um papel mais ativo, rompendo com o estigma de simples receptor de conteúdos e a buscar conhecimentos voltados especificamente aos problemas e objetivos da aprendizagem. Em decorrência dessa nova postura, o estudante passa a desenvolver em seu perfil características como responsabilidade, autoavaliação, ética, trabalho em equipe, ser mais crítico-reflexivo, criatividade e curiosidade científica. Essa proposta pedagógica tem um enfoque no "aprender fazendo", onde a construção do conhecimento está relacionada com a vivência dele.

O estudante A não esteve presente no dia da apresentação, mas gostou bastante do estímulo. Acredita que se fosse feito um trabalho assim nas avaliações, seria bem vantajoso e considerou a ideia bem interessante.

Outro fato foi à interação da turma, pois a problematização integrou mais o grupo, pelo fato de que todos tiveram que interagir. Teve coordenador, membros, redator, para cada área uma pessoa específica. O mais interessante foi o trabalho ser feito em grupo e não apenas individual, que a pessoa tem que se virar. Tiveram que mesclar todas as ideias e chegar a um denominador comum para tentar solucionar cada parte do problema.

As metodologias ativas fundamentam-se em estratégias de ensino baseadas nas concepções pedagógicas reflexivas e críticas, onde se pode interpretar e intervir sobre a realidade, promover a interação entre as pessoas e valorizar a construção do conhecimento, os saberes e situações de aprendizagem (FEUERWERKER; SENA, 2002).

De acordo com os três estudantes entrevistados, as informações para solução das atividades foram tiradas das teorias ensinadas em sala de aula e dos materiais que os professores disponibilizaram, como textos, slides, artigos, destacando que não foi nem preciso acessar a internet para pesquisar.

Para os três estudantes entrevistados, a atividade era um desafio, mas o que tornou as atividades fáceis foi o fato de não ser uma avaliação formal, o que permitiu que o diálogo fluísse, facilitando a troca de informações. 
Tiveram, também, muito auxílio dos professores, o auxílio da pesquisadora e os materiais. Não havia tensão de se estar executando uma prova, em uma avaliação final, ou seja, não havia pressão de uma avaliação semestral. Consideraram mais difícil a hora da explicação das respostas, ou seja, da apresentação das soluções. Consideraram bem tranquilo e bem integrador.

Os estudantes entrevistados afirmaram que o melhor foi que um escutava o outro e houve a liberdade de se expor o que se pensava. Todos conversaram sobre o assunto e expuseram seu pensamento. A proposta do grupo foi a conversa e o respeito.

Os estudantes afirmaram que usaram a internet somente para complementar o trabalho dado em sala ou para ajudar a compreender textos difíceis, na concepção deles. Revelaram que não possuem o costume de ler livros em sala de aula e que a base dos estudos é por meio do portal e pelos slides. Não houve essa necessidade de internet ou algo paralelo para poder fazer o trabalho. Consideraram que o material que os professores deram foi o suficiente.

Os estudantes entrevistados disseram que não tiveram nenhuma dúvida, pois desde o primeiro momento a situação já estava bem explícita. Poderia ter mais de uma resposta porque se tinha a visão do comando e do comandado. Tentou-se olhar os dois lados da situação para poder chegar a uma conclusão.

A única dificuldade citada foi colocar a situação na prática, desde o momento que se tem apenas a teoria, mas em nenhum momento confronto com as duas realidades, até porque no cotidiano eles têm a teoria e a prática todos os dias. Por isso, comentaram anteriormente, se tivesse um trabalho assim no final de cada bimestre seria legal, porque daria para expor mais o pensamento e aplicar a questão em si. Acharam que esse trabalho foi bem proveitoso.

Acrescentaram que a interação do grupo e o convívio de há tempos melhorou com as atividades e que gostariam de todo bimestre ter uma atividade desse tipo. Antes, eles tinham a visão do lado de fora, só da teoria e, com as atividades, puderam vivenciar a situação, considerando bem gratificante. 
Consideraram que a interação dos professores foi perfeita, eles souberam o momento de brincar e de falar sério e foi muito boa a forma como expuseram as matérias para ajudar na resolução do problema. Consideraram que a atividade deveria existir em todos os bimestres, porque os exercícios que os professores passam fixam mais a teoria.

Justamente por se fundamentar no princípio da autonomia, é que a prática da metodologia ativa precisa que o discente desenvolva sua capacidade de gerenciamento e administração do seu próprio processo de formação (FREIRE, 2006). O ensinar, nessa abordagem progressista, que considera o indivíduo como construtor da sua própria história, exige do professor respeito à autonomia de cada estudante (COSTA; SIQUEIRA-BATISTA, 2004). Nesse sentido, a visão do professor sobre o estudante muda, de subordinado e passivo para ativo e coordenador do próprio conhecimento, levando em conta seu conhecimento prévio e sua experiência de vida, ou seja, é o que se pode chamar de construtivismo, quando o estudante constrói o próprio conhecimento e para o professor que não está acostumado, a situação pode ser constrangedora e difícil. 


\section{CONSIDERAÇÕES FINAIS}

A Aprendizagem Baseada em Problemas é uma metodologia que tem como base ensinar os estudantes por meio de problemas profissionais, para os quais se buscam soluções, tendo como fundamentos as teorias ensinadas em sala de aula, ou seja, vivenciam-se na prática todas as teorias transmitidas pelos professores.

Para se trabalhar com essa metodologia, é necessário que o currículo escolar seja baseado em problemas, pois a abordagem formativa é centrada na resolução de problemas, sendo diretriz norteadora em todo processo educativo, buscando confrontar os estudantes, por exemplo, com situações vivenciadas profissionalmente e no dia a dia, devendo ser adaptado à escola, conter um banco de problemas relevantes, tal qual banco de dados, e haver gerência de pessoas e grupos. Além disso, é preciso que os professores estejam preparados e com bagagem cultural suficiente para prover o estudante, pois se esses não estiverem preparados para essa nova dinâmica de ações em sala de aula, podem não conseguir acompanhar o desenvolvimento da turma e o aprendizado dos estudantes.

A utilização da metodologia requer, ainda, adoção dos princípios de aprendizagem cumulativa, aprendizagem integrada, aprendizagem progressiva e aprendizagem consistente. Pode ser usado um protocolo de desenvolvimento, como o que foi usado no presente trabalho, mas que necessita ser melhorado para uso constante, pois esse deve levar em conta o currículo escolar.

Com base neste estudo, foi possível concluir que o elemento mais importante da ABP não é o resultado final, mas o próprio processo de aprendizagem por resolução de problemas, por meio do qual os estudantes aprendem a se tornar aprendizes independentes, ativos e críticos, assim desenvolvendo habilidades e atitudes exigidas na sociedade contemporânea.

Já na metodologia tradicional, o ensino se preocupa mais com a variedade e quantidade de informações do que com a formação do pensamento reflexivo do estudante. O professor é o agente e o estudante é o ouvinte. Mesmo que ele não compreenda o conteúdo, a aula continua e esse nível de compreensão só será visto após as provas. 
A ABP pode ser um caminho para a participação ativa do aluno na construção do conhecimento e a integração entre os conteúdos. Além disto, a ABP, comparada com o método tradicional, apresenta outras características importantes e opostas: aprende-se fazendo e discutindo com o mediador e com os colegas de turma; a utilização de instrumentos de avaliação diferenciados para facilitar e estimular o desempenho dos estudantes; aprendizagem não é por disciplinas, mas por unidades com integração interdisciplinar e a prática.

Com base neste estudo, conclui-se que a Aprendizagem Baseada em Problemas motiva o estudante por fazer parte do contexto dele, assim assumindo um caráter de relevância para a prática profissional.

Diferentemente dos métodos tradicionais que o conhecimento repassado aos estudantes não estabelece relações significativas, os métodos da $\mathrm{ABP}$ possibilitam o desenvolvimento de um profissional mais crítico consigo mesmo e com sua atuação profissional.

Os resultados encontrados pela pesquisa revelaram que a maioria dos professores não teve grandes dificuldades com a utilização do método, pois já praticava ou conhecia as metodologias ativas, no qual há uma integração de todo o conhecimento entre as disciplinas, considerando-o uma experiência positiva e interessante. As dificuldades encontradas por parte dos professores foi por estarem habituados com a metodologia tradicional que é a exigida pela instituição.

Uma vez que a ABP tem a filosofia construtivista em sua essência, há a necessidade de que o professor faça um estudo bastante profundo acerca da filosofia presente na $\mathrm{ABP}$ e, a partir daí, o adapte às necessidades e potencialidades dos estudantes.

Na metodologia ativa, o estudante é o gestor de seu aprendizado e o professor é apenas um facilitador, mediador do conhecimento, que é construído em conjunto, por meio da partilha de ideias, raciocínios, compreensão de cada um, até se chegar a um consenso que satisfaça a necessidade da problemática em questão.

Apesar de um dos professores afirmar que os estudantes têm dificuldade de correlacionar o conteúdo que eles aprendem com aquilo que é instrumento 
para resolver um problema, que eles não sabem dividir tarefas e nem trabalhar em grupo, esse entrevistado afirmou que o protocolo é válido e que o problema está no estudante. Percebe-se, aqui, uma contradição da fala desse professor, ao se comparar com as falas dos estudantes e de outros professores, que consideraram a utilização do protocolo para aplicação do método, um dos fatores decisivos para a promoção do processo de ensino e aprendizagem. Houve consenso geral no que tange ao aproveitamento da turma, no sentido da aprendizagem em relação às outras turmas que usam o método tradicional.

Além disso, percebeu-se que há falta de mais conhecimento por parte do professor sobre o assunto, ou seja, ele precisa se preparar melhor, estudar mais, porque o professor precisa realizar todo um trabalho de preparação até o estudante se acostumar, visto que estão acomodados com o método tradicional, que traz tudo pronto. O professor também possui um conhecimento engessado na metodologia tradicionalista, acostumado com a aceitação passiva por parte do estudante, que não era incentivado a pensar e a construir seu próprio conhecimento. Quando o estudante começa a participar mais ativamente e a questionar mais, o professor se sente acuado, pois a implantação de metodologias ativas no processo de ensino-aprendizagem consiste em enfrentar muitos desafios, pois o estudante passa a ser o protagonista desse processo e os professores assumem o papel de mediadores.

As maiores dificuldades foram relativas ao tempo de aula e ao tempo de aplicação completo do método, pois seria necessário um tempo maior, para que o estudante se acostumasse e o professor se preparasse melhor. Nas falas dos professores, muitos estudantes não possuem boa formação no nível de ensino fundamental e médio e isso dificulta. Na verdade, a dificuldade não é a formação do estudante, mas o esforço que o professor tem que empreender para ensinar, pois primeiro ele precisa se acostumar com o método, adquirir maior conhecimento, para depois ensinar o estudante a pensar por si mesmo, após anos de tradicionalismo passivo. Acostumar o estudante a pensar e a participar de seu próprio aprendizado requer do professor mediador maior flexibilidade e capacidade de articulação, pois estas são ferramentas para alcançar o sujeito crítico e ativo. 
Observou-se que, tanto na visão dos professores como na dos estudantes, foi enorme o interesse pela metodologia aplicada. Os professores acharam que os estudantes foram bastante participativos e se surpreenderam com os resultados, apesar de que, ao final das falas, ficaram indecisos em afirmar que houve impacto na aprendizagem dos estudantes, mas tiveram que concordar porque os resultados das avaliações foram tão significativos que não puderam ser ignorados.

Os estudantes, por sua vez, ficaram muito entusiasmados com a nova metodologia e, pela primeira vez, se sentiram parte da construção do processo de aprendizagem e conhecimento, verificando até que ponto a teoria apresentada em sala de aula os auxiliaria na solução dos problemas apresentados. Acredita-se que foi nesse último ponto que os professores ficaram inseguros, posto que isso resultaria em uma avaliação de seu trabalho como mediadores do conhecimento, visto que, se a teoria ministrada aos estudantes não fosse suficiente, revelaria em uma falha do professor e os estudantes teriam que buscar em outras fontes de pesquisas, material que lhes pudesse auxiliar.

Apesar das dificuldades iniciais, os estudantes gostaram do método que, segundo eles, auxiliou muito na memorização do conteúdo, além de oferecer oportunidade de aplicar a teoria na prática, o que, sem dúvida, prepara com mais qualidade o estudante para a vida profissional e colabora para melhorar o relacionamento entre estudantes e professores.

Os professores também puderam conhecer melhor os estudantes nas atividades práticas, descobrindo talentos que antes não haviam sido percebidos, considerando que o impacto na aprendizagem foi positivo, não só por causa das avaliações, mas pelo desempenho dos estudantes durante as atividades, que buscaram fazer link, não necessariamente com sua disciplina, mas sim com o curso, pois a preocupação era com o modelo que é mais interdisciplinar, relacionando sua disciplina com a de outros professores e do curso em geral.

Observou-se também que alguns professores foram bem resistentes ao método. Essa situação pode revelar insegurança por parte do docente em aceitar a participação mais ativa por parte do estudante; um dos motivos pode ser que 
o docente entenda que, dessa forma, esteja perdendo parte de sua autoridade e poder que a posição de professor lhe oferece, para ter que partilhá-la com o estudante, pois este se torna gerenciador de seu próprio aprendizado e o professor, mero expectador e mediador do conhecimento, em uma abordagem mais construtivista.

É preciso entender que a ABP é uma metodologia de ensino e aprendizagem que emprega problemas da vida real (reais ou simulados) para que o estudante possa aprender por meio da dúvida, deixando de lado o papel de receptor e tornando-se construtor do próprio conhecimento. A ABP pode ser considerada uma metodologia que utiliza situações complexas para instigar os estudantes a pesquisarem soluções para problemas. Ela baseia-se no princípio do uso de problemas como ponto inicial para aquisição do conhecimento, situando a aprendizagem em problemas cotidianos, reforçando do aprendizado já existente.

Essa metodologia incentiva, instiga, provoca o estudante a buscar maior conhecimento para obter soluções aos problemas apresentados e, dessa forma, há ampliação do conhecimento, maior e melhor sociabilização e integração do grupo.

No geral, a utilização da metodologia ABP pelos professores e estudantes gerou bons resultados. Os estudantes gostaram se entrosaram melhor e o aprendizado teve um impacto positivo, mesmo com as dificuldades iniciais.

O estudo mostra-se relevante para os professores, podendo contribuir para a melhoria da sua realidade atual em sala de aula, para os gestores, proporcionando a percepção da mudança de metodologias tradicionais por ativas no curso de Administração e para os estudantes, em especial os da instituição pesquisada, pela oportunidade em participar ativamente de um novo modelo pedagógico, de forma a possibilitar melhor aprendizagem, com formação de indivíduos mais críticos e reflexivos.

Sugerimos que, para novas pesquisas sobre a ABP, seja verificado o impacto dos fatores limitadores no processo de ensino-aprendizagem com a utilização deste método; que sejam analisadas as habilidades e atitudes desenvolvidas nos estudantes que utilizaram este método; e que seja criado um grupo de controle para verificar os resultados das avaliações dos estudantes que utilizaram as metodologias ativas. 


\section{REFERÊNCIAS}

ABREU, M. C.; MASETTO, M. T. O professor universitário em aula: práticas e princípios teóricos. 5. ed. São Paulo: MG Ed. Associados, 1985.

ABREU, J. R. P. Contexto atual do Ensino Médico: metodologias tradicionais e ativas - Necessidades pedagógicas dos Professores e da estrutura das escolas. 105f. 2009. Dissertação (Mestrado em Ciências da Saúde) Faculdade de Medicina. Universidade do Rio Grande do Sul. Porto Alegre.

BEAVERS, A. Teachers learners: implications of adult education for professional development. Journal of College Teaching and Learning, v. 6, n. 7, p. 25-30, 2009.

CABRAL, C. L. O; TEODÓSIO, H. A. As interfaces entre filosofia e pedagogia. In: CINFE - Congresso Internacional de Filosofia e Educação, 5., 2010, Caxias do Sul/RS. Anais... Caxias do Sul/RS, 2010.

COSTA, C. R B. S. F.; SIQUEIRA-BATISTA, R. As teorias do desenvolvimento moral e o ensino médico: uma reflexão pedagógica centrada na autonomia do educando.

Revista Brasileira de Educação Médica, v 28, n 3, p.242-250, 2004.

CYRINO, E. G.; PEREIRA, M. L. T. Trabalhando com estratégias de ensinoaprendizado por descoberta na área da saúde: a problematização e a aprendizagem baseada em problemas. Caderno de Saúde Pública, v. 20, n. 3, p.780-788, 2004.

DIAZ-BORDENAVE, J.; PEREIRA, A. M. Estratégias de ensino-aprendizagem. 28.ed. Petrópolis: Vozes, 2007.

FEUERWERKER, L. C. M.; SENA, R. R. A contribuição ao movimento de mudança na formação profissional em saúde: uma avaliação das experiências UNI. Interface Comunicação, Saúde e Educação, v 6, n 10, p.37-50, 2002.

FREIRE P. Pedagogia da autonomia: saberes necessários à prática educativa. 33.ed. São Paulo: Paz e Terra, 2006.

HMELO-SILVER, C. E. Problem-based learning: what and how do students learn? Educational Psychology Review, v. 16, n. 3, p. 235-266, 2004.

KOLB, D. A. Experimental learning: experience as the source of learning and development. New Jersey: Prentice-Hall, Englewood Cliffs, 1984.

MAMEDE S.; PENAFORTE, J.; SCHMIDT H.; CAPRARA A.; TOMAZ J.B.; SÁ H. Aprendizagem Baseada em Problemas - Anatomia de uma nova abordagem educacional. Fortaleza: Escola de Saúde Pública do Ceará/Ed. Hucitec, 2001.

MITRE, S. M.; BATISTA, R.S. ; MENDONÇA, J.M.G. ; PINTO, N.M.M. ; MEIRELLES, C.A.B. ; PORTO, C.P. ; MOREIRA, T. ; HOFFMAN, L.M.A. Metodologias ativas de ensino-aprendizagem na formação profissional em saúde: debates atuais. Ciência e saúde coletiva, v.13, n.2, p. 2133-2144, 2008.

MIZUKAMI, M. G. N. Ensino: as abordagens do processo. São Paulo: Ed. Pedagógica e Universitária, 1986. 
MOREIRA, M. A. P.; FONTENELE, R. E. S. A aplicação de um método ativo de ensino com a utilização de um simulador empresarial voltado à administração financeira.

Revista Razão Contábil \& Finanças, v. 2, n. 1, p. 1-16, 2011.

NII, L. J.; CHIN, A. Comparative trial of Problem-Based Learning versus Didactic Lectures on clerkship performance. American Journal of Pharmaceutical Education, v. 60, n. 2, p. 162-164, 1996.

RIBEIRO, L. R. C. Aprendizagem baseada em problemas (PBL) na educação em engenharia. Revista de Ensino de Engenharia, v. 27, n. 2, p. 23-32, 2008.

Aprendizagem Baseada em Problemas (PBL): Uma

Implementação na Educação em Engenharia na Voz dos Atores. Tese (Doutorado em Educação) - São Carlos/ SP, Universidade Federal de São Carlos, 2005.

SAKAI, M. H.; LIMA, G. Z. PBL: uma visão geral do método. Olho Mágico, v. 2, n. 5/6, encarte especial, nov. 1996.

SCHMIDT, H. G. Foundation of problem-based learning: some explanatory notes.

Medical Education, v. 27, n. 5, p. 422-432, 1993.

WESTBERG, J.; JASON, H. Collaborative clinical education: the foundation of effective health care. New York: Springer Publishing Company, 1993. 


\section{DADOS DOS AUTORES}

\section{KARINE DE LIMA GUEDES ${ }^{\star}$ karinelguedes@yahoo.com.br}

Mestre em Administração pela Unigranrio

Instituição de vinculação: Universidade do Grande Rio

Rio de Janeiro/RJ - Brasil

Áreas de interesse em pesquisa: Administração, educação e educação à distância.

* Av. Pedro Calmon, 550, Edifício da Reitoria, $8^{\circ}$ andar, sala 833

Itha do Fundão Rio de Janeiro/RJ 21941-901

RUI OTAVIO BERNARDES DE ANDRADE ruiotavio@unigranrio.com.br

Doutor em Administração pela UFSC

Instituição de vinculação: Universidade do Grande Rio

Rio de Janeiro/RJ - Brasil

Áreas de interesse em pesquisa: Processos de Ensino em Administração e

Contabilidade.

\section{ALEXANDRE MENDES NICOLINI alexandre.nicolini@unigranrio.com.br}

Doutor em Administração pela UFBA

Instituição de vinculação: Universidade do Grande Rio

Rio de Janeiro/RJ - Brasil

Áreas de interesse em pesquisa: Processos de Ensino em Administração e

Contabilidade. 